\title{
PRE-PRINT VERSION
}

Günther M., Lüpke L., Stummer C. (2017) Cross-over between scenario analysis and agent-based market simulation for technology planning. In: Proceedings of PICMET '17: Technology Management for Interconnected World. Portland International Conference on Management of Engineering and Technology (PICMET), 1-9.

DOI: 10.23919/PICMET.2017.8125434

This work was presented at the PICMET'17 Conference, held in Portland, Oregon (USA), on July 9-13, 2017, and included in the Conference Proceedings. 


\title{
Cross-Over Between Scenario Analysis and Agent- Based Market Simulation for Technology Planning
}

\author{
Markus Günther, Lars Lüpke, Christian Stummer \\ Bielefeld University, Department of Business Administration and Economics, Bielefeld, Germany
}

\begin{abstract}
Many firms resort to scenario analysis as a tool for supporting strategic technology planning. For this purpose, alternative future scenarios are set up and contrasted with potential courses of action that take into account, for instance, new product features, measures for market introduction, or novel business models. Typically, the fitting between these scenarios and potential (action) portfolios is based on estimations. Enriching this rather limited valuation with outcomes from (agent-based) market simulations may therefore serve as a valuable means for decision support, because simulation results provide much more in-depth information such as product diffusion curves based on the new technologies for each combination of scenario and (action) portfolio over the course of time. The simulation can account for the relevant stakeholders (e.g., consumers) by modeling them as agents with heterogeneous preferences and behaviors. The prospective market development then emerges from the agents' actions and interactions (e.g., their word-of-mouth communication or purchases). We will describe such an agent-based model and discuss its contribution to technology planning by means of application examples based on real-world data.
\end{abstract}

\section{INTRODUCTION}

"The dream of August Comte that the science of social physics could be used to predict the future exactly by observing the past is considered [...] a mere dream, never to be realized." [1]

Scenario analysis and its 'pictures of the future' have been proven as a valuable tool in strategic technology planning; it helps organizations to prepare for eventualities and, thus, to become more flexible and even innovative [2]. However, gaining better information about possible futures is only one element of making better decisions; management must also select an appropriate bundle of actions from among a variety of alternatives in order to meet the challenges described in the pictures of the future.

Our research leads in this direction. We propose combining scenario analysis with agent-based market simulation. This type of simulation is relatively new but has already become quite popular in the context of market introduction of innovations. It can take into account the relevant stakeholders, their heterogeneity and motivations, and their interactions, thus capturing emergent market behavior. Such predictions can then provide the basis for more informed decisions when selecting the "best" bundle of actions to pursue in order to properly meet

Financial support from the German Federal Ministry of Education and Research (BMBF) for our contribution to the research project "itsowlVorZug", as part of the BMBF leading-edge-cluster "it's owl", is gratefully acknowledged (grant no. 02PQ3023). upcoming challenges.

This paper is organized as follows: In Section II, we describe the proposed framework, which consists of one particular approach to scenario analysis combined with a market simulation. In Section III, we introduce the agent-based market model and its core elements. Next, results from a sample application to smart products about to be introduced in a consumer goods market are shown in Section IV. The case is inspired by a real application, but data has been modified. The paper finally concludes in Section $\mathrm{V}$ with a summary, a discussion of limitations, and an outlook to further research.

\section{A FRAMEWORK TO ENRICH SCENARIO ANALYSIS WITH AN AGENT-BASED APPROACH}

In strategic technology planning, scenario analysis has been established as a rather common management tool, especially due to rising complexity and uncertainty regarding the development of markets and business environments [3]. Although scenarios are not supposed to precisely forecast the future [4], they provide illustrations of multiple possible future outcomes and, thus, help to overcome thinking limitations and stimulate strategic thinking [2].

Since the 1960s and 1970s, many different approaches for building scenarios and supporting management in various application cases have been introduced [5] (for the origins and evolution of scenario techniques in long-range business planning, refer to e.g., [6]). Scenarios can be set on several levels of abstraction ranging from sector-, market-, or business environment scenarios to business-specific scenarios (see [7] for an example in an "Industry 4.0" context). The paper at hand is concerned with scenarios as part of strategic technology planning as proposed by [8]. Therein, Gausemeier et al. define a scenario as "a generally intelligible description of possible a situation in the future, based on a complex network of influence factors"; in their approach they follow two principals, systems thinking and multiple futures [8]. Their scenario development process consists of five phases, starting with scenario preparation (phase 1), in which the main target and the object under consideration (e.g., a company, a product, or a technology) is defined. This is followed by the scenario-fields analysis (phase 2), wherein internal as well as external influencing factors are identified, the latter originating from three environments, namely, industry (competitors), industrial environment (comprising suppliers, buyers, substitutes, and new entrants [7]), and global environment (i.e., technology assessment, consumer behavior, or economic performance). To select key factors from typically up to 150 identified influencing factors, an influence analysis/cross-impact matrix 
(e.g., [9-11]) can first be used to help identify dominant factors, subsystems, and critical feedback loops. The factors are then positioned in a system grid, which helps to reveal the roles of the factors within the system and to characterize them as impulsive (levers with strong impact on the system), dynamic (destabilizers that can be used to stimulate system changes), or reactive/inert factors (typically relevant for projects with a short time horizon) [8]. Next (in phase 3), the possible developments for each of the key factors (so-called 'projections') are prognosticated for the specified time horizon and listed in a projection catalogue. In the first step of scenario development (phase 4), contradicted combinations of projections (projection bundles) are created using a consistency analysis. So-called prescenarios are identified using clustering techniques. These projection bundles can also be placed in a future map using multidimensional scaling, which helps the visualization of the various prescenarios. Finally, the scenarios are prosaically described and disruptive events or factors are added. This step can be supplemented by a robustness and sensitivity analysis. In the scenario transfer (phase five), finally, opportunities and threats of each of the scenarios are analyzed and corresponding strategies are formulated.

These strategies might be responsive/preventive, planningoriented, or proactive [12]. In a responsive or preventive strategy, uncertainty is accepted and the organization strives to react quickly and efficiently to environmental changes. This makes it necessary to keep sufficient and flexible resources available, which typically leads to higher cost. The planningoriented strategy is based on the credo that at least some changes can be predicted and therefore specific actions anticipating the forthcoming changes can be taken. The accuracy of the forecast is therefore of particularly high importance. The proactive strategy, finally, builds on the premises that changes are unpredictable. Still, the analysis tries to anticipate events and actions to take in order to influence effects of potentially negative events or to foster the occurrence of positive changes. Makridakis [11] lists five strategic areas ('variables') that can used for fostering (desired) changes, namely, market demand (e.g., marketing or pricing of products, outsmart competitors), reducing dependencies (e.g., vertical integration), research and development (e.g., innovative products), barriers to entry, and financial strength.

In such a proactive strategy, various bundles of actions can be set that might unfold their full potential depending on whether the corresponding scenario closely resembles the 'real' future. We refer to these bundles of actions as 'action portfolios', which may contain differing functionalities of new products (R\&D), activities intended to enhance market penetration (marketing), or new business models (see, for instance, $[13,14]$ and within the context of scenario analysis, [7]). Ultimately, exactly one of these action portfolios can be implemented; thus, decision makers face a selection problem.

In the strategic technology planning process, the portfolios of actions are contrasted side by side with the business-specific scenarios. Currently, it is common practice (e.g., [8]) to evaluate the consistency of diverse portfolios of actions (and thus their assumed effectivity and efficiency) with scenarios (i.e., pictures of the future) holistically on a scale (ranging, e.g., from "++" to "--"). Our framework instead suggests using an (agent-based) market simulation. This allows testing of portfolios of actions on simulated markets over time, thus providing deeper insights into a portfolio's effectivity in a given possible future. Fig 1 schematically depicts this approach of combining scenario analysis and market simulation. The value added by the market simulation is, among other things, that decision makers can learn about the impact of various action portfolios under varying environmental conditions. The outcomes of each combination of action portfolio and scenario can be shown, for instance, by means of diffusion curves over time (see the matrix on the bottom right in Fig 1). Such a simulation approach not only can show market development over time (instead of providing just a snapshot) but can also account for repeat purchases (and, in order to do so, use market share instead of adoption and diffusion curves) or analyze regional differences, the impact on particular customer segments, etc.

Regarding modeling market diffusion, we have opted for a modern agent-based simulation approach instead of resorting to one of the more traditional approaches typically based on differential equations (e.g., $[15,16]$ ), which thus model the diffusion at the aggregate level of the entire population. Such approaches cannot explicitly account for heterogeneity and therefore ignore differences in consumers in terms of individual preferences, behavior, expertise, and geographical position and various connections between consumers. An agent-based approach, in contrast, can overcome such limitations because relevant entities are modeled at the micro-level (for a discussion about the different levels of abstraction, from macro-level to micro-level perspectives, see [17] or [18]). These entities, called agents, act and react to their environment and make decisions based on their limited available (local) information. All their actions (e.g., adoption of a product, repurchase) on the micro-level lead to the emergent behavior (e.g., diffusion patterns, sales rate) at the macroscopic level (also cf. [19-21]). Therefore, agent-based simulation is particularly suitable if interaction between consumers - such as communication within a social network - plays a relevant role [22]. Additionally, such a simulation approach allows capturing of complex structures and dynamics without knowing the exact global interdependencies [17]. For a comprehensive survey of agent-based diffusion models and a more in-depth discussion of their advantages, we refer to [23] or [24].

\section{The Agent-BAsed Model}

In an agent-based market simulation, all relevant participants (e.g., consumers)-modeled as heterogeneous agents - act (e.g., make decisions such as purchasing a product) and interact (e.g., communicate with other consumers) within/with their environment. These agents can represent persons (consumers, intermediaries, opinion leaders), but they can also represent businesses (producers, points of sale) as well as political agents (promoting certain behavior through incentives). All of these influence market behavior and together form emergent system behavior [25]. The variety and number of agent types as well as their options for action are defined by the particular requirements of the market, and thus by specific research questions. 


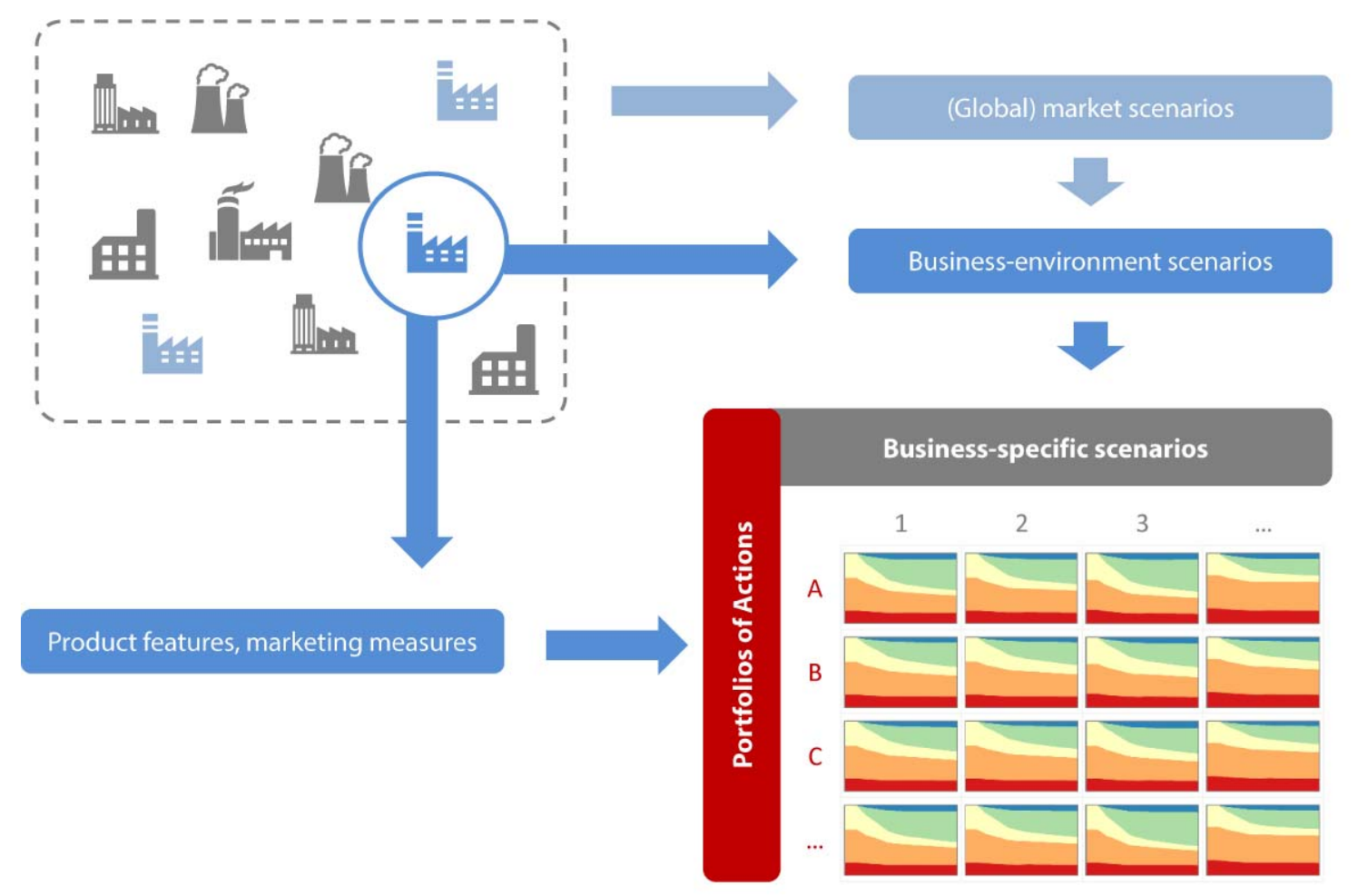

Fig. 1. Combination of Scenario Analysis and Market Simulation

The agents considered in the model at hand are products, points of sales, and heterogeneous and spatially (geographically) distributed consumer agents. Note, based on the requirements of our sample applications and the information received from our project partners, we deliberately do not model multiple producers or intermediaries in our simulation model.

The main model dynamics are triggered by consumer agents. They initiate the purchasing process for a (new) product, in which they evaluate the products at the reachable points of sales and only the products they are aware of based on their limited (local) information. They thus select their 'best' alternative from their own individual perspective. Additionally, they communicate with peers about their received information about the product, which also includes first-hand experience. Consumers receive information from their peers and are also exposed to various marketing measures.

An overview of the main entities and the model dynamics is given in Fig 2 and they are described in the following subsections.

\section{A. Model Entities}

The model at hand allows for multiple products, different points of sale, and heterogeneous consumers who are connected by a social network that structures their interactions.

Products are characterized by various attributes regarding their performance (e.g., 'level of smartness' or 'price') as well as their composition/existence of attributes. For instance, some products might have the attribute 'smartness', whereas others lack this characteristic. The product portfolio can change over time as every product has a predefined availability on the market that is determined by a point of market introduction and a point of discontinuation. Thus, different aspects of technology evolution (e.g., smaller or bigger technological progress between product generations) can be considered and evaluated as managerial action in an action portfolio. Initially and in-line with the 'bounded rationality' of agent-based modeling, consumers are not aware of the availability of products, products' characteristics, or the true performance value of product attributes. Therefore, consumers must gather initial information about a product by either individual communication or by being exposed to marketing activities (directed, undirected, or at the point of sale).

Products can be purchased at various points of sale. Each point of sale offers a predefined portfolio of products within a defined and not necessarily exclusive geographical area. Note that, if necessary, the model allows for capturing multi-channel strategies. For instance, online sales might cover (nearly) the whole market, whereas a physical store might only be available for consumers within a specific range. Additionally, each point of sale might also set individual marketing activities (e.g., making consumers aware of a newly introduced product, a specific attribute, or an attribute's performance) as well as individual pricing strategies. The latter is not activated in our sample application as the products are equally distributed over all points of sale. However, this might be taken into account for other product categories if necessary in order to examine, for instance, heterogeneous pricing or different spatial or timing aspects of a rollout strategy as specific actions under evaluation. 


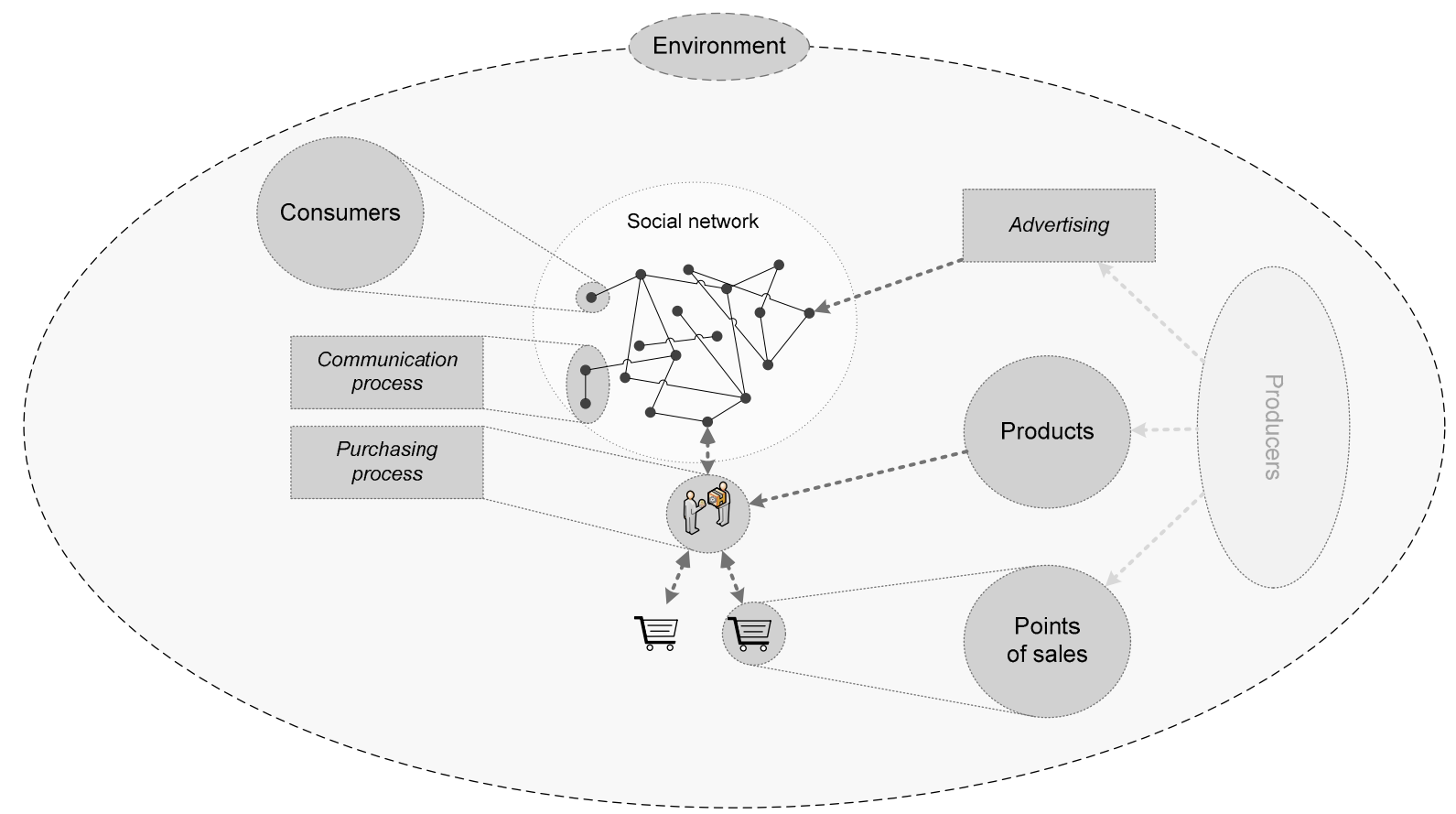

Fig. 2. Model Entities and Model Dynamics

Each consumer has a specific geographic position that limits the eligible points of sale based on individual search radius. Note, as stated earlier, online sales channels can also be set up and used by all consumers. The heterogeneous consumer preferences toward the attributes/products are represented by individual partial utility functions that are modeled in the form of additive utility functions with piecewise marginal utilities. Several products or attributes may be unknown to each consumer and/or can have a higher or lower relevance for each of them.

Initially, when a new product is introduced to the market, consumers are not aware of the product or its characteristics. The awareness of a new product or a product's attributes must be created, through either marketing activities (e.g., mass media, point of sale promotions) or individual communication between consumers. Therefore, when consumers evaluate the (known) products during the purchasing decision based on the product's/attributes' performance, they do not necessarily consider all existing product attributes, as they might not be aware of them. Even though they might not have known about all the product attributes before purchasing the product, they get to know the product's attributes and its (true) performances after the adoption over time through use of the product. Note, not all attributes might be equally observable through first-hand experience and price is the only attribute that is always objectively known to the agents at the time of purchase, as this information is available at the point of sale. Summarizing, information about a product is perceived through a consumer's own (first-hand) experience, marketing activities, and word of mouth (communication between agents).

Consumers are also characterized by individual communication behavior, such as communication frequency, and they weight received information differently based on the source.

\section{B. Model Dynamics}

The main model dynamics comprise advertising, information exchange between consumers via their social network, and the purchasing process.

Advertising as one form of marketing activity can differ by topic (e.g., regarding the addressed products and/or attributes), credibility (e.g., the trustworthiness of the information,), geographic availability, or target group. Advertising does more than spread information among consumers about a product's/attributes' performance in order to influence consumers' assessments. It can also call attention to only certain products or product attributes. For example, when introducing a new generation of a product with new attributes (e.g., 'smartness'), that information must initially be made publicly available.

The simulation framework can model classic forms such as outdoor advertising, advertising in television, radio, and print media, and online advertising, as well as direct marketing such as direct mailings, newsletters, or email. Therefore, activities can also address specific target groups (e.g., personas, opinion leaders) or selected geographical areas. In contrast to word-ofmouth communication, information spread via advertising is unidirectional and typically - as evidence from the marketing literature suggests (e.g., [26]) — has a smaller impact on consumers.

Communication is the information exchange between consumers who are linked within a social network. It may influence them in two ways: First, consumer (agents) become aware of points of sale, brands, products, or product attributes 
about which they might not have known before. Second, their assessment of a product or product's attribute is proven, or updated, by the additional information. A communication event can cover assessments of several product attributes.

The potential communication partners of consumers are determined by the social network in which they are embedded. The connections between agents are bi-directional communication channels, where information is exchanged via word of mouth. The social network can be generated using a small-world network algorithm as proposed by Watts and Strogatz [27] or a scale-free network algorithm as introduced by Barabási and Albert [28]. Both algorithms create networks that match typical characteristics of social networks, albeit with different extents (see [23]). Additionally we consider an extended Barabási-Albert network algorithm - as proposed by Latané et al. [29] and first used by Stummer et al. [30] - in a way that the probability of a connection (and thus a relationship) between two consumers increases with their proximity to each other. Thus, this algorithm accounts for the geographical position of the agents. Note, as in most agentbased simulations, the number of consumers as well as the ties between agents in the social (communication) network remains constant over time. Further, so-called opinion leaders are characterized by a variety of social contacts and communication activities. Their exchange frequency is above average, as is their credibility, for instance, due to their job and/or (suspected) knowledge and experience of a product. They are important hubs in the social network.

Regarding the purchasing process, our model considers the five phases of new product adoption proposed by Rogers [31]: (i) the knowledge phase (i.e., learning about the existence of an innovation and its basic functions); (ii) the persuasion phase (i.e., forming an opinion based on given information); (iii) the decision phase (i.e., deciding about adoption of the product); (iv) the implementation phase (i.e., using the product); and (v) the confirmation phase (i.e., gathering information to reaffirm the consumer's decision). In covering all five phases (particularly the latter two), we go farther than most previous agent-based models [30, 32].

The first two phases are influenced by advertising and word of mouth, whereas the decision phase is initiated when an existing product reaches its (stochastically determined) end of life. Then, consumers face a discrete choice problem in which all known and available products at a chosen point of sale will be taken into consideration. For each product, the expected utility value is determined by an additive utility function considering the (individual) perceived values of each known product attribute and the individual agent's preferences. A (small) stochastic error term is added to represent any further influencing factors not explicitly considered. Finally, the product with the highest utility value will be purchased. Furthermore, a non-purchase option can be added and/or normative influence (cf. [33]) may play an important role in the purchasing process. In our sample application, both have been omitted for simplicity.

During the implementation and confirmation phases, the consumer's attitudes regarding the purchased product will be influenced by his first-hand experience. On one hand, this has an influence on future purchase decisions. On the other hand, the consumer's experiences will be spread within the social network via word of mouth.

\section{ILLUSTRATIVE RESULTS}

\section{A. Implementation}

The above-described market model was implemented in AnyLogic 7 (www.anlyogic.com), a java-based software that provides functionalities for setting up agent-based simulations. While the core simulation uses AnyLogic, we have 'outsourced' a few support functionalities that are particularly expensive computation-wise to additional software tools, allowing us to speed up their execution. This holds, for instance, for the algorithm that renders proper geographical positioning of the consumer agents and for the creation of the social network. Results (i.e., geographical positions of agents and connections of each consumer agent with its peers) are then imported by the AnyLogic tool upon execution when needed. Moreover, we have created a tailored (external) tool to evaluate simulation logs of purchasing and communication events which provides us with more flexibility when processing results (e.g., it automatically aggregates sales data and variances, and it creates corresponding diagrams). Alternatively, the log files could have also been analyzed in R, SPSS, or any spreadsheet program.

\section{B. Sample Application: Data Acquisition and Parameterization}

The sample application presented here, smart products, and its parameterization is inspired by, but due to confidentiality not fully based on, real-world data. Generally, this data can be derived from corporate and market insights or through empirical studies (e.g., qualitative or quantitative surveys, conjoint analysis). A detailed illustration of how to collect the necessary data for parameterization and validation goes beyond the scope of this contribution. General aspects of parameterization and validation of an agent-based simulation as well as its real-world applicability_reflecting uncertainties and inaccuracies in assumptions about future market conditionshave been given in the literature (cf. [30]).

Our sample application reflects a consumer goods market with three initial products ('discount', 'standard', and 'premium') and two more smart products ('smart standard' and 'smart premium'), which are introduced later on. The geographic area modeled (and simulated) is a regional urban part of Germany

Smart products are goods equipped with various information technology components, especially microchips, software, or sensors. They can collect and process as well as produce data and information (cf. [34]). Several smart products are already available today, for instance, ubiquitous smartphones, service robots for homes and gardens (e.g., automatic lawnmowers) or assistance systems in cars for parking. Other smart products are pushing into niche markets: intelligent refrigerators (LG Smart ThinQ), intelligent toothbrushes (Oral B Bluetooth Toothbrush), intelligent smoke detectors (Nest), intelligent floors that report emergencies or 
burglaries (SenseFloor), or connected tennis rackets (Babolat Play). Finally, intelligent products will enable new business models that, for example, propose services (e.g., pay-per-use) instead of products and address new market segments (for a discussion on smart products from a management science perspective, see [35]).

In the sample application, the products are characterized by four attributes: 'quality', 'functionality', 'price', and 'smartness'. In particularly, 'quality' and 'functionality' are concepts influenced by many other aspects (e.g., lifetime, service, range of functions, or size/weight). We follow [36] in using a reduced attribute-set, as many (also important) decisions are based ultimately on only a few criteria. Furthermore, we refer to a probability distribution to capture the lifetime of each product, which drives the initialization of a purchase transaction. The average lifetime is set to two years.

Generally, the individual parameterization of consumer agents could be derived by, for example, conjoint analysis (cf. $[30,37,38]$ ) or by prototypes (so called 'personas') for each group of consumers with similar characteristics and usage behavior [39]. In the latter case, each agent is assigned to a persona; the assignment probability corresponds to the proportion of the represented persona within the market. The agent is then parameterized with slight variations of the persona's characteristics so that all agents based on one persona have similar but not identical parameters.

Consumer agents are geographically distributed according to the population, in this case, household density based on German postal code areas. In the sample application, agents are randomly distributed within a $10 \mathrm{~km}$ radius around the geographical center of the postal code area. Although this approach involves inaccuracies, it fulfils the intended purpose. If more detailed information on individual households is available or necessary (e.g., population density based on streets), this approach can be easily adapted.

Following the geographical distribution of the agents, the social network is generated via a scale-free Barabási-Albert network [28] extended by a geographical component and using a previously verified and used parameter set (cf. [30, 40]).

For the purposes of this sample application, we have only modeled consumer agents and have ignored producers and intermediaries. Furthermore, points of sale are not considered explicitly; thus, there are no limitations for the consumer regarding the selection of (alternative) products. As a result, we simulate a market in which all products can be obtained under identical conditions, (e.g., an online platform) and the purchase

\begin{tabular}{ccc}
\multicolumn{2}{c}{ TABLE I: } & TRENDS IN PARAMETERIZATION FOR EACH \\
\hline COMPANY-ENVIRONMENT SCENARIO
\end{tabular}

decision is not influenced, for example, by intensive interaction with a salesperson.

\section{Scenarios and Action Portfolios}

The derived company-environment (company-specific) scenarios are based on sectoral scenarios for the energy market, developed as part of the research project "itsowl-VorZug". These four scenarios describe different futures; two scenarios are, to varying degrees, positive (scenario 1: 'regional expansion as launch pad' and scenario 3: 'the success story'), while the other two are more negative (scenario 2: 'implementation deficits require significant improvements' and scenario 4: 'low market flexibility and cost pressure prevent innovation leap').

Note that the parameterization of the agents is influenced by these scenarios (see Table I). For example, in scenarios 1 and 3 , the preference of the agents for smartness as a product attribute is higher and additionally, the initial attitudes of the agents toward the 'smartness' of the products is more positive. In the more negative scenarios 2 and 4, the parameters are chosen to be opposite of those of scenarios 1 and 3 . Additionally, awareness of smart products, or the attribute 'smartness', does not exist in each scenario at the start of the simulation, but such awareness will be created by marketing campaigns as part of the product launch and especially by word of mouth during the simulation.

These business-environment scenarios are contrasted to different action portfolios (portfolios of measures) representing different market entry strategies. In this sample application, we vary only the attributes 'price' and 'level of smartness'; we also vary marketing measures for the new products ('smart standard' and 'smart premium') in the four different portfolios. Furthermore, various other measures may be used to widen the action portfolio, e.g., shaping of product attributes, dynamic pricing strategies, temporal and spatial variation of marketing activities, or business model innovation.

In portfolio $\mathrm{A}$, the new products are introduced to the market with a high price and level of smartness, accompanied by a comprehensive marketing campaign. Portfolio B utilizes an adverse strategy with a low price and level of smartness and product introduction is accompanied by only limited marketing activities. Portfolio $\mathrm{C}$ and portfolio $\mathrm{D}$ introduce the products at a middle price and vary only in the level of smartness and marketing (see Table II).

In the four sample portfolios, the price is increased and decreased within a range of 5 to 15 percent. The 'level of smartness' of the products in portfolios B and D is halved in

TABLE II: TRENDS IN PARAMETERIZATION FOR EACH ACTION PORTFOLIO

\begin{tabular}{cccc}
\hline Portfolio & Price & Smartness & Marketing \\
\hline A & $\uparrow$ & $\uparrow$ & $\uparrow$ \\
B & $\downarrow$ & $\downarrow$ & $\downarrow$ \\
C & $\leftrightarrow$ & $\uparrow$ & $\downarrow$ \\
D & $\leftrightarrow$ & $\downarrow$ & $\uparrow$ \\
\hline
\end{tabular}




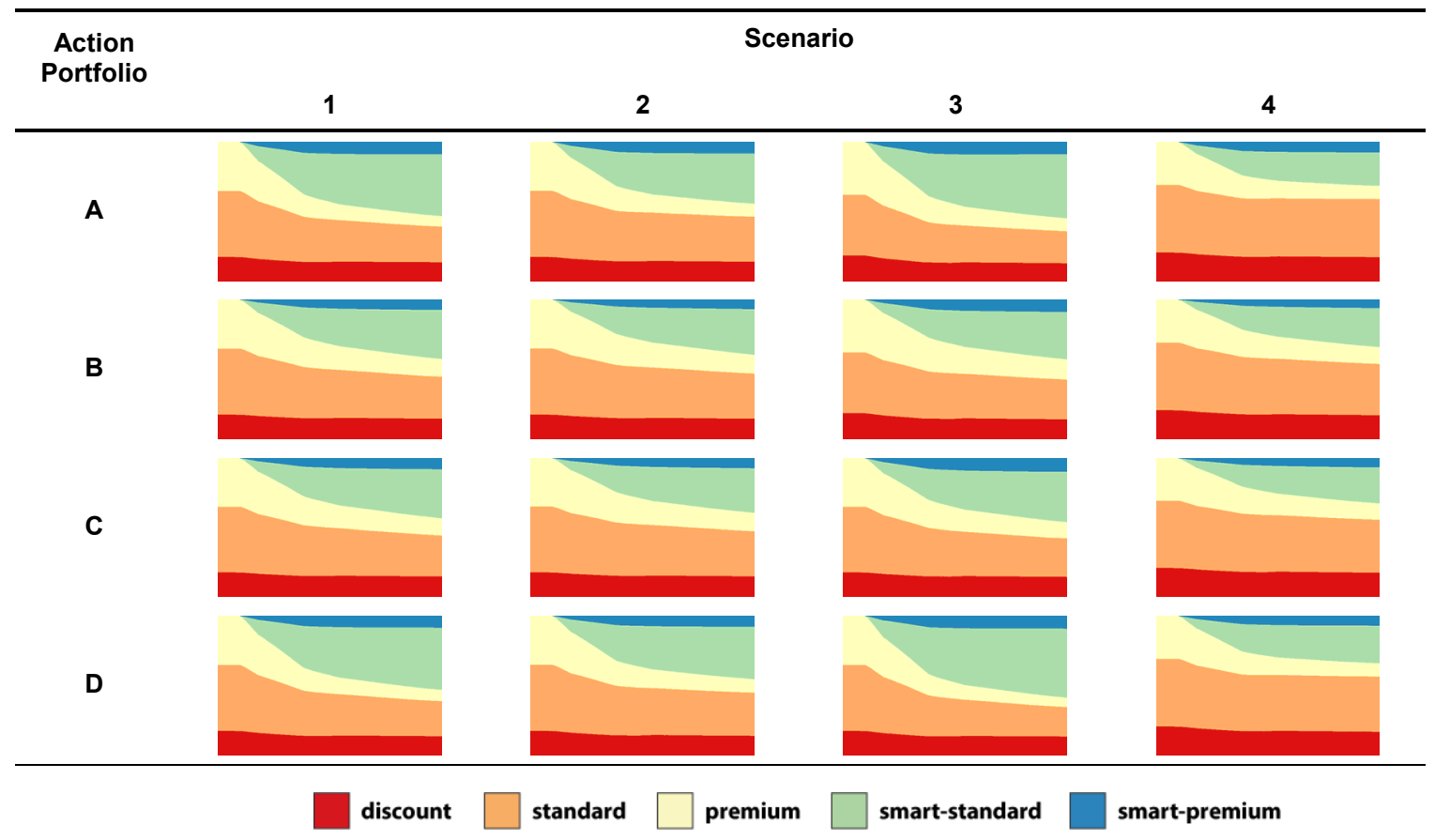

Fig. 3. Market Share: Company-Specific Scenarios and Action Portfolios

comparison to the 'level of smartness' in portfolios A and C. In all portfolios, the marketing activities focus exclusively on the two new products and the attribute 'smartness'; marketing activities vary in relation to their intensity and duration between each portfolio and thus in their effectiveness.

The simulated time horizon is set to 10 years and 8,000 consumers, resp. agents were used (representing households with a factor 10,000:1).

\section{Simulation Results}

Each combination of an action portfolio and a scenario was run ten times using different seeds; in Fig 3-5 we provide just the arithmetic mean. The run-time per simulation run is about 13 seconds; a complete simulation of all 16 combinations with ten repetitions each is around 34 minutes on a current PC system (Core i5, 16 GB RAM, SSD).

The simulation result, which shows the development of market shares for each action portfolio per companyenvironment scenario, is shown in Fig 3.

The simulation results match the expectations: the more positive the attitude toward smart products in the given scenarios, the higher the market share of those products. More interesting are the differences both between the scenarios and in relation to the portfolios. For example, a comparison of portfolios C and D shows that a lower 'level of smartness' of the new introduced products cannot be compensated by more comprehensive marketing, at least not with the simulated marketing measures. This is proven in Fig 4 via a comparison of the respective market shares of portfolios $\mathrm{C}$ and $\mathrm{D}$ in scenario 3.
In portfolio $\mathrm{C}$ (Fig 4, left) the new products are equipped with a high 'level of smartness' but are combined with relatively less marketing (minus 50\%). In contrast, the new products in portfolio D (Fig 4, right) are equipped with a lower 'level of smartness' (minus 50\%), but with a more comprehensive marketing campaign. The price remains identical in both portfolios. Obviously, in this very positive environment for smart products, the simulated marketing campaigns are inadequate to compensate for the lower 'level of smartness' of the new products. The market share of the new products at the end of the simulation ( 10 years) in portfolio $\mathrm{C}$ is around 35 percent higher than in portfolio $\mathrm{D}$.

Due to the micro-level approach of agent-based simulation, the data can not only show the shift of market shares between products but also give more insights into the groups of consumers (personas) that are responsible for these shifts. For example, based on the switching behavior shown in Fig 5, it can be seen that in scenario 3 , where consumers are very openminded to those new (smart) products, an unexpected changeover from 'discount' products to 'smart standard' products takes place. Accordingly, the attribute 'smart', or the 'level of smartness', provides a sufficient incentive for

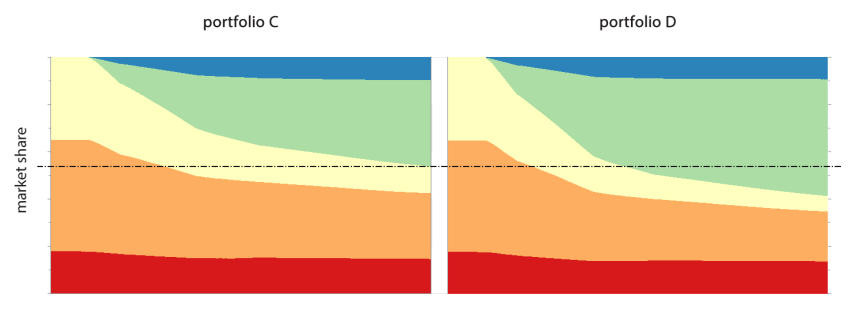

Fig. 4. Comparing Action Portfolio C and Portfolio D in Scenario 3 

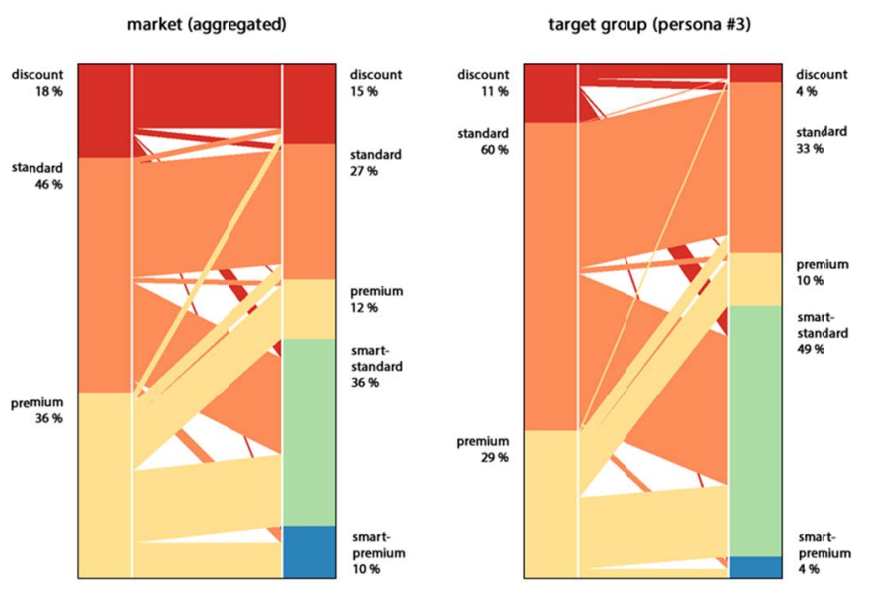

Fig. 5. Switching Behavior in Action Portfolio C of Scenario 3

switching to a higher product category. These analyses can also be done either for the whole market (Fig 5, left) or for each group of consumers/personas (Fig 5, right). Furthermore, possible differences in selected (geographic) regions or in relation to a combination of various consumer characteristics can be analyzed in more detail to gain insights applicable to the rollout strategy of a new product.

The analysis of the switching behavior shows that a bit more than half of the original 'discount' product owners buy at least one new (smart) product within the simulation horizon of 10 years. In this sample application, it may be due to the fact that there is no 'smart discount' product, and the attraction of a new (smart) product overrides the price; this scenario is considered very positive. One implication of these simulation results may be that an additional 'smart discount' product should be introduced. Whether a possible risk of cannibalization between the 'smart discount' and 'smart standard' products exists could be simulated with a little effort based on additional information obtained by the decision maker.

In summary, Fig 6 shows the diffusion of new (smart) products over time (portfolio $\mathrm{C}$ in scenario 3). The rapid adoption rate is remarkable and is based on the quick first two stages ('knowledge' and 'persuasion') in the adoption process [31] of this sample application. If consumers arrive at a sufficiently high utility value, they will immediately buy the new (smart) product without seeking any further information. The low variance between the ten simulation runs and thus the robustness of the simulation is remarkable (additional robustness analyses have been performed). The mean of all repetitions is shown as bold curve in Fig 6 .

In a real-world application, this process would start with a heterogeneous set of action portfolios in order to get a better 'feeling' for their efficiency and effectiveness in the different scenarios. If a promising strategic thrust is identified, it can be refined and enhanced using diverse portfolios of measures. Each of these variants can be simulated and analyzed with reasonable effort.

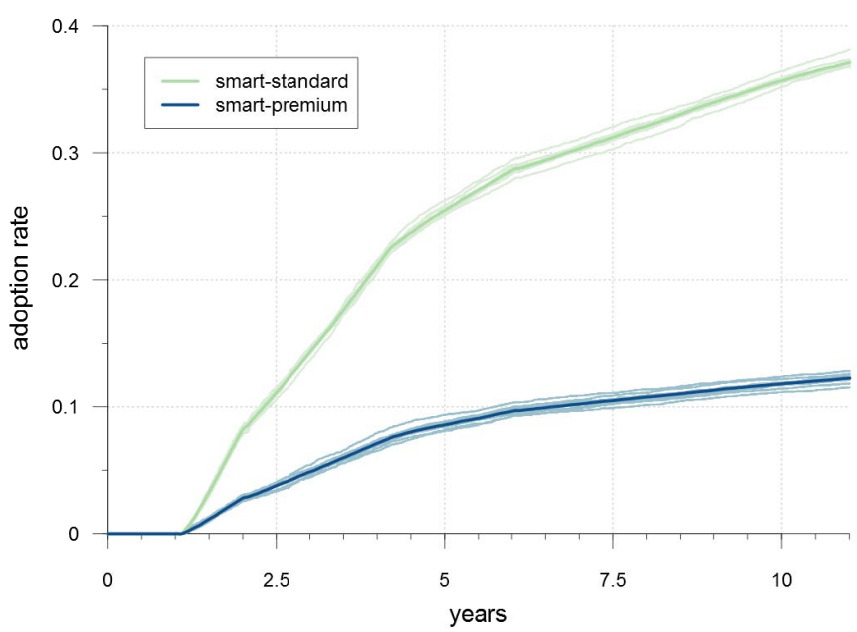

Fig. 6. Diffusion Process of the Products 'Smart Standard' and 'Smart Premium' for Action Portfolio C of Scenario 3

\section{CONCLUSION}

In our work, we have proposed the combination of common scenario analysis with agent-based market simulation in order to better support decision makers in technology planning. The simulation replaces the common 'manual' consistency review of actions and offers a much richer basis for (strategic) decisions in that it can capture complex market behavior that emerges from actions of and interactions between consumers. Thus, managers receive additional information about the effectiveness of the action portfolios under consideration and they may learn about prospective consumer behavior in different regions and/or among specific consumer groups. The applicability of the tool has been illustrated by means of an example (modified) real products under development in the leading-edge cluster "it's owl" in Germany.

Although this approach of integrating an agent-based market simulation into scenario analysis brings some interesting new insights and advantages, it also comes with challenges and additional costs. First, the parameterization of the simulation according to the individual characteristics of a company, its products, and the corresponding markets is not trivial. In further applications, it might be necessary to adapt the market model, which could make it necessary to add functionalities to the simulation tool. Furthermore, the required data must be collected, which could be laborious and costly. Finally, whether the (additional) benefit of applying such a tool justifies the associated costs should always be critically considered. In cases in which complexity is high and interdependencies and interactions of stakeholders play a major role, this approach can bring valuable new insights. However, in some other markets (e.g., capital goods markets), this might not be the case. In particular, if the market mechanism does not embed an emergent behavior, other methods may provide comparable results at lower costs.

Further research may be worthwhile in multiple directions. First, it obviously would be interesting to test our approach with more companies from diverse markets. Ideally, such a collaboration should allow the validation of simulation results 
by comparing them with real market trends, thus strengthening trust in the tool's predictions. Regarding the market model, we plan to integrate active producer agents who show distinct (strategic) behavior. Competitors in the simulation thus mayas a result of actions of the other market players and according to their own strategic attitude, but also with regard to their own technological capabilities and the respective market accesschoose from a range of strategic options. Finally, the product category of our sample application, smart products, provides a very appealing field for further research on management implications (for a paper on corresponding research perspectives, see [35]). This may include, for instance, further empirical studies on consumer preferences and barriers to adoption of smart products (see, e.g., [41]).

\section{ACKNOWLEDGMENTS}

We thank our colleagues from the three project partners, Heinz Nixdorf Institute (HNI) at the University of Paderborn, Scenario Management International (ScMI), and UNITY Consulting \& Innovation, all of which have supported our work by providing their expertise in scenario analysis, for their cooperation.

\section{REFERENCES}

[1] Makridakis, S. G. and S. C. Wheelwright; Forecasting methods for management, 5th ed., New York: Wiley, 1989.

[2] Amer, M., T. U. Daim, and A. Jetter; "A review of scenario planning," Futures, vol. 46, pp. 23-40, 2013.

[3] Rigby, D. and B. Bilodeau; "A growing focus on preparedness," Harvard Bus. Rev., vol. 85, pp. 21-22, 2007.

[4] Schoemaker, P. J. H.; "When and how to use scenario planning: A heuristic approach," J. Forecast., vol. 10, pp. 549-564, 1991.

[5] Van Notten, P. W. F., J. Rotmans, M. B. A. Van Asselt, and D. S. Rothman; "An updated scenario typology," Futures, vol. 35, pp. 423443, 2003.

[6] Bradfield, R., G. Wright, G. Burt, G. Cairns, and K. Van Der Heijden; "The origins and evolution of scenario techniques in long range business planning," Futures, vol. 37, pp. 795-812, 2005.

[7] Gausemeier, J., B. Amshoff, C. Dülme, and M. Kage; "Strategic planing of market service in the context of industry 4.0," "Strategische Planung von Marktleistungen im Kontext Industrie 4.0," in Vorausschau und Technologieplanung (10. Symposium für Vorausschau und Technologieplanung). vol. 334, Gausemeier, J., Ed., Paderborn: HNIVerlagsschriftenreihe, 2014, pp. 5-36.

[8] Gausemeier, J., A. Fink, and O. Schlake; "Scenario management: An approach to develop future potentials," Technol. Forecasting Soc. Change, vol. 59, pp. 111-130, 1998.

[9] Schlange, L. E.; "Linking futures research methodologies," Futures, vol. 27, pp. 823-838, 1995.

[10] Godet, M.; "The art of scenarios and strategic planning: Tools and pitfalls," Technol. Forecasting Soc. Change, vol. 65, pp. 3-22, 2000.

[11] Godet, M.; Scenarios and strategic management, London: Butterworths, 1987.

[12] Makridakis, S. G.; Forecasting, planning, and strategy for the 21st century, New York: The Free Press, 1990.

[13] Chesbrough, H.; "Business model innovation: Opportunities and barriers," Long Range Plann., vol. 43, pp. 354-363, 2010.

[14] Teece, D. J.; "Business models, business strategy and innovation," Long Range Plann., vol. 43, pp. 172-194, 2010.

[15] Norton, J. A. and F. M. Bass; "A diffusion theory model of adoption and substitution for successive generations of high-technology products," Manage. Sci., vol. 33, pp. 1069-1086, 1987.

[16] Bass, F. M.; "A new product growth for model consumer durables," Manage. Sci., vol. 15, pp. 215-227, 1969.

[17] Borshchev, A. and A. Filippov, "From system dynamics and discrete event to practical agent based modeling: Reasons, techniques, tools," in 22nd International Conference of the System Dynamics Society, Oxford,
UK, eds.: Kennedy, M., G. W. Winch, R. S. Langer, J. I. Rowe, and J. M. Yanni, July 25-29, 2004.

[18] Davis, J. P., K. M. Eisenhardt, and C. B. Bingham; "Developing theory through simulation methods," Acad. Manage. Rev., vol. 32, pp. 480-499, 2007.

[19] Mcfadden, D.; "Conditional logit analysis of qualitative choice behavior," in Frontiers in economics, Zaremba, P., Ed., New York: Academic Press, 1974, pp. 105-142.

[20] Mahajan, V., E. Muller, and F. M. Bass; "New product diffusion models in marketing: A review and directions for research," J. Marketing, vol. 54, pp. 1-26, 1990.

[21] Bonabeau, E.; "Agent-based modeling: Methods and techniques for simulating human systems," Proc. Natl. Acad. Sci., vol. 99, pp. 72807287, 2002.

[22] Macy, M. W. and R. Willer; "From factors to actors: Computational sociology and agent-based modeling," Annu. Rev. Sociology, vol. 28, pp. 143-166, 2002.

[23] Kiesling, E., M. Günther, C. Stummer, and L. M. Wakolbinger; "Agentbased simulation of innovation diffusion: A review," Central Europ. J. Operations Res., vol. 20, pp. 183-230, 2012.

[24] Wakolbinger, L., C. Stummer, and M. Günther; "Market introduction and diffusion of new products: Recent developments in agent-based modeling," Int. J. Innovation Tech. Manage., vol. 10, p. 1340015, 2013.

[25] Axelrod, R.; The complexity of cooperation: Agent-based models of competition and collaboration, Princeton, NJ: Princeton University Press, 1997.

[26] Day, G. S.; "Attitude change, media and word of mouth," J. Advertising Res., vol. 11, pp. 31-40, 1971.

[27] Watts, D. J. and S. H. Strogatz; "Collective dynamics of 'small-world' networks," Nature, vol. 393, pp. 440-442, 1998.

[28] Barabási, A.-L. and A. Réka; "Emergence of scaling in random networks," Science, vol. 286, pp. 509-512, 1999

[29] Latané, B., J. H. Liu, A. Nowak, M. Bonevento, and L. Zheng; "Distance matters: Physical space and social impact," Pers. Soc. Psych. Bull., vol. 21, pp. 795-805, 1995.

[30] Stummer, C., E. Kiesling, M. Günther, and R. Vetschera; "Innovation diffusion of repeat purchase products in a competitive market: An agentbased simulation approach," Europ. J. Oper. Res., vol. 245, pp. 157-167, 2015 .

[31] Rogers, E. M.; Diffusion of innovations, 5. ed., New York: Free Press, 2003.

[32] Günther, M., "Diffusion of multiple technology generations: An agentbased simulation approach," in 2016 Portland International Conference on Management of Engineering and Technology (PICMET), eds.: Kocaoglu, D. F., T. R. Anderson, T. U. Daim, D. C. Kozanoglu, K. Niwa, and G. Perman, pp. 2931-2940, 4-8 Sept. 2016, 2016.

[33] Cialdini, R. B. and N. J. Goldstein; "Social influence: Compliance and conformity," Annual Review of Psychology, vol. 55, pp. 591-621, 2004.

[34] Rijsdijk, S. A. and E. J. Hultink; "How today's consumers perceive tomorrow's smart products," J. Prod. Innovation Manage., vol. 26, pp. 24-42, 2009.

[35] Dawid, H., R. Decker, T. Hermann, H. Jahnke, W. Klat, R. König, et al.; "Management science in the era of smart consumer products: Challenges and research perspectives," Central Europ. J. Operations Res., pp. 1-28, 2016.

[36] Gigerenzer, G.; Belly decisions: The intelligence of the unconscious and the power of intuition, Bauchentscheidungen: Die Intelligenz des Unbewussten und die Macht der Intuition, Munich: Bertelsmann, 2007.

[37] Garcia, R. and W. Jager; "From the special issue editors: Agent-based modeling of innovation diffusion," J. Prod. Innovation Manage., vol. 28, pp. 148-151, 2011.

[38] Zhang, T., S. Gensler, and R. Garcia; "A study of the diffusion of alternative fuel vehicles: An agent-based modeling approach," J. Prod. Innovation Manage., vol. 28, pp. 152-168, 2011.

[39] Cooper, A.; The inmates are running the asylum: Why high-tech products drive us crazy and how to restore the sanity, Indianapolis: Sams Publishing, 1999.

[40] Günther, M., C. Stummer, L. M. Wakolbinger, and M. Wildpaner; "An agent-based simulation approach for the new product diffusion of a novel biomass fuel," J. Oper. Res. Soc., vol. 62, pp. 12-20, 2011.

[41] Kaldewei, M. and C. Stummer; "How adoption and diffusion of a smart product may be affected by referring to customer empowerment activities or the status as a start-up company," unpublished. 